\title{
Barriers to prevention of cardiovascular disease in primary care settings in Argentina
}

\author{
Daniel Ferrante, ${ }^{1}$ Jonatan Konfino, ${ }^{2}$ Bruno Linetzky, ${ }^{2}$ \\ Ana Tambussi, ${ }^{2}$ and Sebástian Laspiur ${ }^{2}$
}

Suggested citation Ferrante D, Konfino J, Linetzky B, Tambussi A, Laspiur S. Barriers to prevention of cardiovascular disease in primary care settings in Argentina. Rev Panam Salud Publica. 2013;33(4):259-66.

\begin{abstract}
Objective. To identify main barriers to preventing cardiovascular disease and implementing clinical practice guidelines in primary care, to pilot implementation of a tailored enactment of the adapted World Health Organization guidelines to prevent cardiovascular disease, and to assess the impact of the intervention in risk stratification.

Methods. A qualitative study was done with decision makers, health professionals, and staff from five primary health care centers, who were interviewed to identify the main barriers. A tailored intervention to apply the guidelines was then designed and implemented. To assess the impact of the intervention on risk factor screening, a before-and-after analysis was performed through a records review of independent samples of patients aged 40 years or older attending each center.

Results. The main barriers identified were lack of awareness of guidelines and lack of knowledge about preventing cardiovascular disease, communication problems within health teams, lack of motivation, and organizational problems. Before $(n=226)$ and after $(n=234)$ the intervention, screening of the main risk factors increased: blood pressure measurement from $44.3 \%$ to $72.6 \%$, cholesterol measurement from $20.7 \%$ to $49.7 \%$, smoking status assessment from $20.4 \%$ to $56.1 \%$, diabetes status assessment from $25.5 \%$ to $93.6 \%$, and previous vascular event status from $33.2 \%$ to $74.3 \%$. Global risk stratification was not done at baseline, compared with $45.1 \%$ after the intervention.

Conclusions. The main barriers identified were useful in designing a tailored intervention. Although no clinical outcomes were evaluated, this study shows that the implementation is feasible, with increased risk stratification as a first step at better patient management.
\end{abstract}

Key words Cardiovascular diseases; primary prevention; disease prevention; Argentina.

Cardiovascular diseases are the primary cause of death and burden of disease in most developing countries (1).

\footnotetext{
1 Coordinador Programa Nacional de Prevención y Control de Enfermedades Cardiovasculares, Ministerio de Salud, Buenos Aires, Argentina. Send correspondence to: Daniel Ferrante, dferrante@msal.gov.ar

2 Dirección de Promoción de la Salud y Control de Enfermedades No Transmisibles. Ministerio de Salud, Buenos Aires, Argentina.
}

In Argentina, they cause $32 \%$ of overall deaths (2). Evidence about the effectiveness of treatments to prevent cardiovascular disease in patients with and without previous cardiovascular events is compelling (3-7). Yet, in routine clinical practice, prescription of and adherence to these interventions are low (8-10). Screening of risk factors and risk stratification is the first step to identify patients at risk of cardiovascular events, but according to observational studies reflecting clinical practice in Latin America, screening and risk stratification strategies are not disseminated (11).

In Argentina, according to National Risk Factor Surveys, measurement of major risk factors is low compared with that in developed countries. Only $68.4 \%$ of adults had their blood pressure mea- 
sured in the past year, and the share was even lower in the public health sector $(57.4 \%)$ (12). Similar problems were observed with regard to cholesterol screening. Among subjects with a high risk of cardiovascular events, in a national registry of 7289 patients, only $44 \%$ had their blood pressure controlled, and 19\% met targets for low density lipoprotein cholesterol (13).

Although guidelines are considered useful tools to improve health care, there are several barriers to implementing them. According to a systematic review of studies performed in developed countries that assessed barriers for guideline implementation, the most frequent barriers were time constraints and lack of applicability because of patients' characteristics or a clinical situation (14). Several reports describe specific barriers to guidelines for prevention of cardiovascular disease $(15,16)$.

These barriers might differ from those in developing countries. Lack of awareness and knowledge were not identified as the most frequent barriers in developed countries, but they could be one of the most relevant barriers in the scenario described here. Barriers to implementation of clinical practice guidelines, as well as implementation strategies, have been poorly studied in developing countries.

Several strategies have been shown to increase adherence of health personnel to recommendations, such as good quality guidelines, credible and clear recommendations (14), reminders (17), personal detailing (18), and audit feedback (19). In a recent systematic review, tailored interventions addressing barriers have been shown to improve professional practice (20), but all studies have low external validity for developing countries.

In 2009, Argentina's Ministry of Health adapted the World Health Organization (WHO) guidelines for prevention of cardiovascular disease (21). But before this guideline was implemented, the main barriers to cardiovascular disease prevention and the effectiveness of different clinical practice guideline implementation strategies aimed at overcoming these barriers were assessed.

The aim of this study was to identify the main barriers to cardiovascular disease prevention and implementation of cardiovascular disease prevention guidelines in primary health care and to assess the effectiveness of tailored implementation of the WHO guidelines addressing these barriers. Specific objectives were to identify the main barriers to cardiovascular disease prevention and clinical practice guideline implementation in primary care, to pilot a tailored implementation of the adapted WHO guidelines, and to assess the effectiveness of the intervention implemented in screening practices.

\section{MATERIALS AND METHODS}

\section{Setting}

Five public primary health care centers (PHCs) in Argentina were included. They were located in medium and large urban areas in different provinces. These centers had a minimum structure of at least physicians, nurses, and administrative staff and a volume of at least 1000 visits per month.

\section{Design}

The study included two phases. The first one aimed to identify barriers and to propose interventions to implement the adapted WHO guidelines through a qualitative study. The second phase assessed the effectiveness of the implementation of interventions tailored to the main barriers. This evaluation consisted of a cross-sectional before-andafter analysis in the same PHCs.

First phase. Initially, a qualitative study was implemented. In-depth, face-to-face interviews were done using a semistructured guide including a set of domains related to potential barriers, prespecified by the research team, drawn from the literature review and dealing with barriers to cardiovascular disease prevention and the chronic disease model (12) (see Annex 1). The interviews were administered to all personnel at each PHC, including physicians, nurses, and administrative staff, and to decision makers at local levels, including primary health care area coordinators and relevant decision makers at county secretaries of health.

The qualitative study approach was based on the grounded theory $(22,23)$, and semistructured interviews were implemented for data collection. Although a saturation criterion was followed according to this theory to guide the number of interviews to be conducted, all staff at PHCs and relevant decision mak- ers were included as key informants for the interviews.

All interviews were digitally audiorecorded for verbatim transcription and qualitative analysis. The guide used for interviews is included in the Annex 1.

For the qualitative phase, the initial content of the interviews was analyzed, and a category tree was constructed to code the data collected. After data reduction, a narrative report of obtained results was done, and the analysis was triangulated with an independent researcher $(24,25)$.

Barriers were classified in different domains, taking into consideration the chronic disease model when possible (26) to be used as input for tailored implementation of the $\mathrm{WHO}$ guidelines.

Second phase. This phase was a crosssectional before-and-after study, including a baseline survey and a final survey. After barriers were identified, a baseline quantitative analysis was done to assess the level of risk factor identification and management before the intervention in a random sample of adult patients. After the intervention, a new random sample of patients was drawn to evaluate risk factor assessment, stratification, and management.

\section{Participants}

At each PHC, medical, nursing, and administrative records of attending patients aged 40 years or older were selected during a period of two weeks, using systematic sampling and varying the selection interval in relation to the volume of patients at each center, with the following inclusion criteria:

- Subjects aged 40 years or older, both sexes

- Patients with or without a previous cardiovascular event

- Patients who were at follow-up at each PHC (two or more previous visits), disregarding the reason for the visit

Independent samples of patients were selected at baseline and one year after implementation of the guidelines.

\section{Design of tailored intervention and end points}

Initially considered a priori were those interventions with the highest level of evidence, such as academic detailing, 
reminders, audit feedback, and patientoriented strategies, as mentioned above.

Academic detailing included an outreach visit to each center, with one-onone training in the chronic disease model and cardiovascular disease prevention guideline with all personnel, using implementation tools (medical record, reminders, tools for patients) and practical examples.

Reminders were located in every room at each PHC and were delivered personally with explanations to each member of the team.

Audit feedback was provided during follow-up according to preliminary results and all personnel were informed that final results would be assessed and communicated back to them.

Patient-oriented strategies included education materials for patients, delivered by nurses or administrative staff in waiting rooms, and a patient diary that included all their risk factors, laboratory results, medication, and follow-up visits.

The final intervention was tailored according to the barriers identified in the first qualitative phase. All interventions were implemented in each PHC, but the intensity of each component was adjusted according to the main barrier at each site. For barriers related to knowledge, academic detailing was prioritized. In the case of motivational barriers, reminders and audit feedback actions were prioritized. When patient involvement in care was considered a relevant barrier, more patient-oriented interventions were implemented.

Selected end points were related to the performance of care in relation to screening and measurement of main risk factors and risk stratification, as suggested by the WHO guidelines adapted for Argentina.

Primary end points were:

- Blood pressure measurement at least in the past year

- Cholesterol measurement performed at least once

- Smoking status assessed in the past year

- Diabetes status assessed in the past year

- Assessment of body mass index

- Assessment of dietary habits

- Assessment of level of physical activity

- Global risk stratification performed using risk factor data
Secondary end points were risk factor targets according to the WHO guidelines adapted for Argentina.

\section{Data collection}

The qualitative phase planned to interview all PHC personnel and decision makers. To evaluate patient screening and stratification, for each patient reviewed, both at baseline and before the intervention samples, the following data were collected through a clinical records review (including medical, nurse, and administrative records) performed by an independent observer at each PHC:

\section{- Demographics: age, sex}

- Screening of risk factors in clinical records, nursing and administrative records (blood pressure measurement, cholesterol measurement, smoking status, diabetes status, cardiovascular event status)

- Risk factor levels and targets

- Risk stratification performed using a global risk approach

At the end of the implementation phase, feedback was given to all professionals at participating PHCs. Professionals were interviewed for their views about the impact of the interventions on their daily work.

\section{Analysis methods and ethical considerations}

In-depth interviews were analyzed using qualitative analysis following the grounded theory framework. Interviews were performed by independent observers at each center and examined by an external analyst. Triangulation was used with the project coordinator.

Interviews were coded using software for qualitative data analysis for both anticipated and emergent domains (Atlas Ti version 5). A coding framework was developed in advance.

To estimate the effect of the intervention on the process measures selected, pre- and post-intervention patient samples were compared with chi square tests used for independent samples. These measures were compared without and with adjustment by age, sex, known risk factors, and comorbidity.

Baseline assessment of blood pressure, cholesterol, and glycemia was estimated from the National Risk Factor Survey 2005 (27). The effect of the intervention was expected to be moderate since interventions were not going to be intensive. In a recent systematic review (19), there was a $54 \%$ increase in desired health interventions through tailored implementation of clinical practice guidelines. This study was more conservative in estimating the size of the effect.

Hence, the following assumptions were used to estimate an increase in assessment of risk factors for the impact of the implementation:

- Blood pressure measurement: $60 \%$ to $75 \%$

- Smoking status assessed: $50 \%$ to $70 \%$

- Cholesterol measurement: $55 \%$ to $75 \%$

- Assessment of history of diabetes: $55 \%$ to $75 \%$

At least 200 subjects were needed at baseline, and another 200 were needed at the end of the intervention to detect these differences with $80 \%$ power and a two-sided alpha error of 0.05 .

This protocol was approved by a local ethics committee (Clínica y Maternidad Suizo Argentina Ethics Committee). Informed consent was requested for participants in interviews, and it was exempted for patients according to national regulations due to review of patient data on records. The identity and data of each participant were kept confidential and anonymous for the analysis.

\section{RESULTS}

The study was conducted between May 2010 and May 2011.

\section{Identification of barriers}

In the qualitative phase, 15 physicians, 20 nurses, 10 social workers, 5 PHC managers, and 5 area managers from every participating PHC were included. Lack of knowledge about cardiovascular disease prevention and specifically about guidelines on the topic was considered a very important barrier. The concept and utilization of a clinical practice guideline were not clear for health professionals and in none of the five PHCs were any guidelines used for cardiovascular disease prevention (the following paragraphs, verbatim from the interviews, follow the description of each 
barrier related to each example and identified in the qualitative analysis).

\section{"I am not aware of any guide to manage risk factors." [nurse]}

Another barrier identified was difficult access of health professionals to relevant information, especially in a practical format that allowed them to make decisions. Acceptance of strict guidelines was viewed as a potential threat to independent decision making.

"At this health center we don't have enough time to keep us up to date with new evidence of guidelines." [attending family physician]

Lack of time to be up to date with the latest recommendations was also considered a barrier related to a high burden of work. This barrier was also related to difficult access to information in an easyto-use format.

"We don't have enough time to read and follow any guidelines. We rely on our own best judgment." [attending clinician]

"We have a lot of workload in order to allow us to review guidelines for each visit." [nurse]

Lack of motivation was another barrier, particularly for physicians. Practice guidelines were considered as tools that limited their decision making, and physicians were not familiar with the global risk approach proposed by the guidelines. Mostly, they preferred the management of isolated risk factors.

"I am not motivated to read a guideline to treat my patients. I prefer to rely on my own knowledge and experience." [attending clinician]

"We are overwhelmed with urgent social and health problems and we can't prioritize prevention activities." [social worker]

Communication problems were reported on health professionals' teams, causing a lack of coordination in patient care among physicians, nurses, and social workers and a lack of knowledge sharing within health teams.
"We usually don't work in close collaboration with physicians and administrative staff due to communication problems due to our work overload." [administrative staff]

Delivery of care was not adapted to chronic conditions. Almost all patients' visits were considered unplanned, dealing with emerging issues and acute health problems.

"Patients usually prioritize urgent health problems and not prevention actions. We have to respond to this demand." [decision maker]

Also related to possibilities of follow-up of chronic medical problems, organizational barriers were identified as not allowing the reorientation of primary care following the chronic disease model, with poorly organized follow-up visits.

"Our model of care is based on satisfying the demand of patients, mainly acute problems, without a focus on chronic condition follow up." [decision maker]

Low quality of administrative, nursing, and medical records was also prioritized as a barrier for case management. Although medical records were used (on paper) in all centers, data on risk factor management and risk stratification were not systematically recorded and used to manage patients.

Pending results and goals were not registered in relation to cardiovascular disease risk factors.

"We don't have information systems in order to help us to follow up and manage patients with risk factors." [attending family physician]

Other, more structural barriers were common to all centers, such as lack of personnel, high perceived workload, barriers in reference and counter-reference mechanisms to perform diagnostic tests, and availability of proper infrastructure in centers.

"At our primary health care centers, we do not have appropriate resources to follow cardiovascular prevention guidelines, particularly with keeping an information system and performing laboratory tests." [nurse]

\section{Description of pilot intervention tailored to barriers}

Several interventions were implemented at each PHC to attempt to overcome the barriers identified (Table 1 ). Centers were visited and interventions were implemented through the following activities:

- For lack of knowledge and difficult access to updates and guidelines on cardiovascular disease prevention, academic detailing was implemented. This detailing included two full-day visits to each PHC and provision of personalized training to every health professional, including physicians, nurses, and administrative staff, at their place of work and ensuring the use of supporting materials for guideline implementation. It included review of recommendations, examples of cases, training in the use of supporting tools, discussion about patients' goals and therapies, and discussion of the roles of each team member at each PHC.

- Toaddress lack of time to keepup to date and difficult access to information during decision making, pocket guidelines, reminders, and flowcharts were introduced at each office (physicians and nurses), summarizing the key recommendations (http://www.msal.gov. ar / ent/images / stories / equipossalud/pdf/2012-08-21_consultorioriesgo-cardiovascular.pdf).

- Audits and continuous feedback were included to enhance motivation.

- A specific chart was included in the medical records of patients with pending risk factor assessment and for patients at high risk of cardiovascular disease to facilitate the organization of care and goals in risk factor measurement and management.

- Regarding provision of services, scheduling was organized according to risk factor goals (i.e., results of pending studies), and patients not attending a scheduled visit were called or visited by a social worker.

- Patient-oriented interventions were implemented through education and communication materials in waiting rooms, such as posters and leaflets (http:/ / www.msal.gov.ar/images / stories/ryc/graficos/0000000281cntafiche_sala-espera_estimacion-rcv. pdf) emphasizing self-care, self-risk 
TABLE 1. Barriers identified and tailored interventions selected, Argentina, 2010-2011

\begin{tabular}{|c|c|}
\hline Barrier & Intervention \\
\hline \multicolumn{2}{|l|}{ Knowledge } \\
\hline $\begin{array}{l}\text { Lack of familiarity with guidelines and lack of } \\
\text { awareness }\end{array}$ & Academic detailing for all personnel \\
\hline Lack of agreement with guideline approaches & $\begin{array}{l}\text { Reminders for offices, including flowcharts and } \\
\text { summary of main recommendations }\end{array}$ \\
\hline \multicolumn{2}{|l|}{ Attitudes } \\
\hline Lack of agreement with guideline approaches & $\begin{array}{l}\text { Academic detailing for all primary health care center } \\
\text { personnel }\end{array}$ \\
\hline Lack of motivation & $\begin{array}{l}\text { Audit and feedback with positive reinforcement of } \\
\text { achievements }\end{array}$ \\
\hline Communication problems within the team & $\begin{array}{l}\text { Standard procedures for organization of care, printed } \\
\text { support material }\end{array}$ \\
\hline \multicolumn{2}{|l|}{ Behavior } \\
\hline Patient factors & $\begin{array}{l}\text { Communication and education material for patients: } \\
\text { learning materials in waiting rooms, self-care diaries } \\
\text { for patients }\end{array}$ \\
\hline \multicolumn{2}{|l|}{ Environmental factors } \\
\hline $\begin{array}{l}\text { Lack of time, lack of resources, organizational } \\
\text { constraints, organization of care }\end{array}$ & $\begin{array}{l}\text { Administrative changes allowing more scheduled visits, } \\
\text { reference and counter-reference mechanisms. }\end{array}$ \\
\hline Record quality & $\begin{array}{l}\text { Tools for high-risk patients } \\
\text { Tools for prioritizing pending issues } \\
\text { Standardization of records }\end{array}$ \\
\hline
\end{tabular}

stratification, and demand of risk factor management to the health care team. Patients were given a diary to write down their medications, pending topics, risk factor goals, and scheduled visits (http://www.msal.gov.ar/ ent/images/stories/equipos-salud/ pdf/2012-08-21_consultorio-riesgocardiovascular.pdf). All adults visiting a PHC during the study period (7 128 visits in the five PHCs) received general education materials. A total of 528 highrisk patients in the five PHCs were identified in the study period and given education interventions. A total of 422 $(80 \%)$ patients provided completed feedback in their diaries at follow-up visits, including their medications, risk status, and next appointment.

\section{Pre- and post-analysis: risk stratification and risk factor control}

At baseline, a sample of 226 patients was included. Mean age was 53 years and $66.7 \%$ were women. Distribution according to global cardiovascular disease risk and WHO guidelines was: low risk $63.9 \%$, moderate risk $28.1 \%$, high risk $8 \%$. Smoking status was assessed in only $20.4 \%$ and blood pressure was measured in $44.3 \%$. In those whose blood pressure was measured, $45.1 \%$ were diagnosed as hypertensive and in only $33.3 \%$ of them was blood pressure controlled (lower than
$140 \mathrm{mmHg} / 90 \mathrm{mmHg}$, since no global risk stratification was implemented to consider targets according to risk).

Cholesterol measurement was performed in only $20.7 \%$ of patients. In those whose cholesterol was measured, $21.1 \%$ had a diagnosis of high cholesterol. Targets could not be evaluated due to a lack of risk stratification, but cholesterol level was considered high (using a cut point of $240 \mathrm{mg} \%$ ) in $21.1 \%$ of subjects whose cholesterol was measured.

Only $25.2 \%$ had their diabetes status screened, and $11.2 \%$ of them were diagnosed as diabetic. Only 22\% had their body mass index assessed, and in these patients $48.3 \%$ presented as overweight. Dietary habits were assessed in 17\%, and from these subjects only $4.8 \%$ were eating five or more servings of fruit and vegetables a day. Only $11 \%$ had their physical activity level assessed, and $54.5 \%$ of them were insufficiently active. Previous vascular event status was reported in only $33.2 \%$ of patients.

Global risk stratification was not done for any patient before implementation of the guideline. Risk factors were managed in an isolated manner.

A year after the baseline evaluation, 234 subjects were included, drawing an independent sample of the same PHCs. Mean age was 54 years and $69.7 \%$ were women. Distribution according to global cardiovascular disease risk and WHO guidelines was: low risk $62.4 \%$, moderate risk $26.9 \%$, high risk $10.7 \%$ (no significant difference compared with the baseline population).

Blood pressure was measured in $72.6 \%$ of subjects (significant increase from baseline, $P<0.0001$ ) (Table 2). In those whose blood pressure was measured, $39.4 \%$ had a diagnosis of hypertension, and $40.2 \%$ of them had their blood pressure controlled according to WHO guidelines; it was evaluable only in subjects whose risk stratification was completed.

Cholesterol was measured in $49.7 \%$ of subjects (significant increase from baseline, $P<0.0001)$. In those patients whose cholesterol was measured, $35.2 \%$ had a cholesterol higher than what is recommended in WHO guidelines $(320 \mathrm{mg} \%$ with an absolute risk lower than 20\%, and $190 \mathrm{mg} \%$ in those with an absolute risk higher than 20\%), and only $30.1 \%$ met cholesterol targets, also evaluable only in subjects whose risk stratification was completed.

After the intervention, smoking status was assessed in $56.0 \%$ of subjects (significant increase from baseline, $P<0.0001$ ).

In $93.6 \%$ of patients, diabetes status was reported. Among them, 9.1\% were diagnosed as diabetic (significant increase from baseline, $P<0.0001$ ).

Body mass index was assessed in $48.3 \%$ of patients, dietary habits in $47.0 \%$ of patients, and physical activity level in $36.3 \%$ of subjects after the intervention (significant increase from baseline, $P<0.0001)$.

Presence or absence of a previous cardiovascular event was reported in $74.3 \%$ of subjects (significant increase from baseline, $P<0.0001)$. In these subjects, $6.4 \%$ had a previous event.

Risk stratification was done according to the guidelines used in $45.1 \%$ of patients (significant increase from baseline, $P<0.00001)$.

Adjusted analysis by age, sex, and education did not show significant results (data not shown).

Physicians, nurses, and administrative staff were interviewed after the implementation phase and final data collection. They were asked if the interventions were helpful in overcoming the perceived barriers. All of them reported that interventions helped them to follow the guidelines more easily, facilitated access to information during patients' visits, provided easier access to patients' 
TABLE 2. Process indicators of risk factor screening, Argentina, 2010-2011

\begin{tabular}{|c|c|c|c|c|c|c|c|}
\hline \multirow[b]{2}{*}{ Indicator } & \multicolumn{3}{|c|}{ Pre-intervention $(n=226)$} & \multicolumn{3}{|c|}{ Post-intervention $(n=234)$} & \multirow[b]{2}{*}{$P$ value } \\
\hline & No. & $\%$ & $95 \% \mathrm{Cl}^{\mathrm{a}}$ & No. & $\%$ & $95 \% \mathrm{Cl}^{\mathrm{a}}$ & \\
\hline $\begin{array}{l}\text { Blood pressure } \\
\text { measurement in past year }\end{array}$ & 100 & 44.2 & $37.6-50.9$ & 170 & 72.6 & $65.1-77.0$ & $<0.0001$ \\
\hline $\begin{array}{l}\text { Cholesterol measurement in } \\
\text { past year }\end{array}$ & 47 & 20.7 & $15.6-26.6$ & 116 & 49.6 & $42.9-56.1$ & $<0.0001$ \\
\hline $\begin{array}{l}\text { Diabetes assessment in } \\
\text { past year }\end{array}$ & 57 & 25.2 & $19.6-31.4$ & 219 & 93.6 & $89.6-96.3$ & $<0.0001$ \\
\hline $\begin{array}{l}\text { Tobacco use assessment in } \\
\text { past year }\end{array}$ & 46 & 20.4 & $15.3-26.2$ & 131 & 56.0 & $49.3-62.4$ & $<0.0001$ \\
\hline $\begin{array}{l}\text { Assessment of body mass } \\
\text { index }\end{array}$ & 50 & 22.1 & $16.9-28.1$ & 113 & 48.3 & $41.7-54.9$ & $<0.0001$ \\
\hline $\begin{array}{l}\text { Assessment of healthy } \\
\text { eating }\end{array}$ & 39 & 17.2 & $12.5-22.8$ & 110 & 47 & $40.5-53.6$ & $<0.0001$ \\
\hline $\begin{array}{l}\text { Assessment of physical } \\
\text { activity }\end{array}$ & 25 & 11.1 & $7.3-15.9$ & 85 & 36.3 & $30.1-42.8$ & $<0.0001$ \\
\hline $\begin{array}{l}\text { Status of cardiovascular } \\
\text { event evaluated in past } \\
\text { yearb }\end{array}$ & 75 & 33.2 & $27.1-39.7$ & 174 & 74.3 & $68.3-79.8$ & $<0.0001$ \\
\hline $\begin{array}{l}\text { Risk stratification performed } \\
\text { in past year }\end{array}$ & 0 & 0 & $N A^{c}$ & 106 & 45.2 & $38.8-51.9$ & $<0.0001$ \\
\hline
\end{tabular}

data for reference, and allowed more patients to participate in the process of care.

\section{DISCUSSION}

The main barriers to cardiovascular disease prevention in primary health care were related to knowledge and attitudes of health professionals, lack of information for health professionals, low-quality medical records, and organization of care without a chronic disease focus. A tailored intervention targeted to these barriers was able to moderately improve care in terms of measurement of risk factors and global risk stratification. Although an improvement in these process indicators was observed, both at baseline and after intervention levels of measurement, control of risk factors was far from optimal. Global risk stratification increased, but management was still based on individual risk factor levels.

Clinical practice guidelines could be tailored, although the intensity of the implementation could have been higher. A moderate effect was observed in process indicators related to increased screening of risk factors and risk stratification, but the final results suggest that more profound changes in the health sector and more intense implementa- tion strategies may be needed for wider implementation.

In developing countries, a recent study reported that physicians were reluctant to use risk stratification tools for decision making in cardiovascular disease prevention (28). However, studies addressing barriers for implementation of cardiovascular disease prevention guidelines in developing countries were not found. A recent review of barriers for implementation of clinical practice guidelines (29) identified only 1 study in developing countries out of 38 studies included in the review, which studied shared decisions in psychiatry practices.

This study has several important limitations. The indicators measured reflect only the process behind risk stratification (risk factor measurement), and the design used, adapted to funds available, did not provide the opportunity to evaluate the impact of this intervention on risk factor control in a cohort of subjects, in a randomized trial, or on reduction in events in follow-up.

Another limitation is the number of professionals and PHCs included. Although the five PHCs were selected to represent different regions of Argentina, the inclusion of only five centers in one country can make claims of external validity weak. Similar barriers could be found in other settings, but the inter- ventions need to be tailored to address specific local barriers. However, results from qualitative studies are relevant at the local level, and similar protocols could be adapted to evaluate barriers before guideline implementation at each site.

Another limitation is related to the use of medical records, since some health interventions might not be documented in them. However, a follow-up form for patients was added to medical records to improve data quality and minimize this limitation.

Although these results were useful as a pilot study to guide implementation of the WHO cardiovascular disease prevention guidelines in Argentina, more research is needed to adapt implementation of cardiovascular disease prevention guidelines in primary care settings in developing countries and to enhance patients' adherence to effective therapies in chronic diseases. These results show that more intense interventions may be needed, addressing more structural barriers that developing countries face, such as availability of trained professionals, infrastructure, equipment, funding, and management. After these results were available, the strategies proposed were adapted and implemented in different settings in PHCs in Argentina.

Since the increase in the world's burden of cardiovascular-related diseases can be attributed to the growth of these conditions in developing countries, and primary health care plays a central role in cardiovascular disease prevention, more research is needed to assess not only intermediate results but also clinical outcomes in this area.

In conclusion, a pilot implementation of adapted WHO cardiovascular disease prevention guidelines in Argentina addressing main barriers to implementation is feasible and suggests moderate effects in the process of care. Implementing these strategies can be useful to reorient primary health care to address the chronic disease epidemic that most developing countries face. It can be relevant to assess barriers and target interventions to enhance guideline implementation at each setting, since barriers and interventions studied in developed countries do not necessarily apply directly to developing countries.

\section{Conflict of interests. None.}


ANNEX 1. Guide for in-depth interview with health professionals and nurses
1. Knowledge of clinical practice guidelines
A. What, for you, is a clinical practice guideline?
B. What clinical practice guidelines do you know?
C. What cardiovascular prevention clinical practice guidelines do you know?

\section{Attitudes toward clinical practice guidelines}

A. How useful do you think a clinical practice guideline is?

B. What are the reasons, in your opinion, why health professionals do not use clinical practice guidelines? What are the main barriers for prevention of cardiovascular disease and use of guidelines?

C. What could be helpful to increase the use and adoption of clinical practice guidelines at your center?

\section{Behavior}

A. What elements do you think could be implemented to facilitate the use of a clinical practice guideline for prevention of cardiovascular disease in your center?

B. What conditions would make it easier for you to use a clinical practice guideline for prevention of cardiovascular disease in your daily practice?

C. What changes do you think would be required to enable you to use a clinical practice guideline for prevention of cardiovascular disease in your daily work?

\section{Guide for in-depth interview with decision makers}

A. What elements do you think could be implemented to facilitate the use of a clinical practice guideline for prevention of cardiovascular disease at the health care center you coordinate?

B. What conditions would make it easier for you to use a clinical practice guideline for prevention of cardiovascular disease in the daily practice of health care centers?

C. What changes do you think would be required to enable health professionals to use a clinical practice guideline for prevention of cardiovascular disease in your daily work?

\section{REFERENCES}

1. World Health Statistics 2011. Geneva: WHO; 2011.

2. Ministerio de Salud. Agrupamiento de causas de mortalidad por division politico territorial de residencia, edad y sexo: Argentina año 2009. Buenos Aires: Ministerio de Salud; 2009. Available from: http://www.deis.gov. ar/publicaciones/archivos/Boletin131.pdf Accessed 1 August 2011.

3. Taylor F, Ward K, Moore TH, Burke M, Davey Smith G, Casas JP, et al. Statins for the primary prevention of cardiovascular disease. CochraneDatabaseSyst Rev.2011;1:CD004816.

4. Cholesterol Treatment Trialists' (CTT) Collaboration, Baigent C, Blackwell L, Emberson J, Holland LE, Reith C, et al. Efficacy and safety of more intensive lowering of LDL cholesterol: a meta-analysis of data from 170,000 participants in 26 randomised trials. Lancet. 2010;376(9753):1670-81.

5. Antithrombotic Trialists' (ATT) Collaboration, Baigent C, Blackwell L, Collins R, Emberson J, Godwin J, et al. Aspirin in the primary and secondary prevention of vascular disease: collaborative meta-analysis of individual participant data from randomised trials. Lancet. 2009;373(9678):1849-60.

6. Wright JM, Musini VM. First-line drugs for hypertension. Cochrane Database Syst Rev. 2009;3:CD001841.

7. Yusuf S, Peto R, Lewis J, Collins R, Sleight P. Beta blockade during and after myocardial infarction: an overview of the randomized trials. Prog Cardiovasc Dis. 1985;27(5):335-71.

8. Esposti LD, Saragoni S, Benemei S, Battachi P, Geppetti P, Di Bari M, et al. Adherence to antihypertensive medications and health outcomes among newly treated hypertensive patients. Clinicoecon Outcomes Res. 2011;3:47-54.

9. Lopez-Carmona D, Bernal-Lopez M, ManceraRomero J, Jansen-Chaparro S, PortalesFernandez I, Baca-Osorio AJ, et al. Compliance with cardiovascular drug prevention measures in a general population: the Multidisciplinary Intervention in Primary Care (IMAP). Eur J Prev Cardiol. 2012;19(5): 1074-81.

10. Lee HY, Cooke CE, Robertson TA. Use of secondary prevention drug therapy in patients with acute coronary syndrome after hospital discharge. J Manag Care Pharm. 2008;14(3):271-80.

11. Silva $\mathrm{H}$, Hernandez-Hernandez R, Vinueza $\mathrm{R}$, Velasco M, Boissonnet CP, Escobedo J, et al. Cardiovascular risk awareness, treatment, and control in urban Latin America. Am J Ther. 2010;17(2):159-66.

12. Second National Risk Factor Survey. Ministry of Health, Buenos Aires, Argentina. Available from: http://www.msal.gov.ar/ent/images/ stories/vigilancia/pdf/fr_encuesta-nacionalfactores-riesgo-2011.pdf Accessed 11 March 2012.

13. Rey R, Oberti P, Costa H, Picarel A, Marconcini G, Mulaci A, et al. Cumplimiento de metas en prevención primaria y secundaria en Argentina. Análisis del estudio OFFICE. Rev Argent Cardiol. 2004;72(supl 3).

14. Gravel K, Légaré F, Graham ID. Barriers and facilitators to implementing shared decisionmaking in clinical practice: a systematic review of health professionals' perceptions. Implement Sci. 2006;1(16):1-12.
15. Hobbs FDR, Erhardt L. Acceptance of guideline recommendations and perceived implementation of coronary heart disease prevention among primary care physicians in five European countries: the Reassessing European Attitudes about Cardiovascular Treatment (REACT) survey. Fam Pract. 2002;19:596-604.

16. Mosca L, Linfante AH, Benjamin EJ, Berra K, Hayes SN, Walsh BW, et al. National study of physician awareness and adherence to cardiovascular disease prevention guidelines. Circulation. 2005;111(4):499-510.

17. Shojania KG, Jennings A, Mayhew A, Ramsay CR, Eccles MP, Grimshaw J, et al. The effects of on-screen, point of care computer reminders on processes and outcomes of care. CochraneDatabaseSystRev. 2009;3:CD001096.

18. Thomson O'Brien MA, Oxman AD, Davis DA, Haynes RB, Freemantle N, Harvey EL. Educational outreach visits: effects on professional practice and health care outcomes. Cochrane Database Syst Rev. 2000;2: CD000409.

19. Jamtvedt G, Young JM, Kristoffersen DT, Thomson O'Brien MA, Oxman AD. Audit and feedback: effects on professional practice and health care outcomes. Cochrane Database Syst Rev. 2003;3:CD000259.

20. Shaw B, Cheater F, Baker R, Gillies C, Hearnshaw H, Flottorp S, et al. Tailored interventions to overcome identified barriers to change: effects on professional practice and health care outcomes. Cochrane Database Syst Rev. 2005;3:CD005470.

21. World Health Organization. Prevention of cardiovascular disease: pocket guidelines for 
assessment and management of CVD risk. Geneva: WHO; 2007.

22. Quinn Patton M. Qualitative research and evaluation methods. 3rd ed. Thousand Oaks, California: Sage Publications; 2002.

23. Oktay J. Grounded theory. Oxford: Oxford University Press; 2012.

24. Oppermann M. Triangulation: a methodological discussion. Int $\mathrm{J}$ Tourism Res. 2000;2(2):141-6.

25. Conde F, Pérez Andrés C. La investigación cualitativa en salud pública. Rev Esp Salud Pública. 1995;69:145-9.
26. Wagner EH. Chronic disease management: what will it take to improve care for chronic illness? Eff Clin Pract. 1998;1(1):2-4.

27. Ministerio de Salud de la Nación. Encuesta Nacional de Factores de Riesgo 2005. Buenos Aires: Ministerio de Salud de la Nación; 2005. Available from: http://www.msal.gov.ar/ ent Accessed 30 September 2012.

28. Sposito AC, Ramires JA, Jukema JW, Molina JC, da Silva PM, Ghadanfar MM, et al. Physicians' attitudes and adherence to use of risk scores for primary prevention of cardiovascular disease: cross-sectional survey in three world regions. Curr Med Res Opin. 2009;25(5):1171-8

29. Légaré F, Ratté S, Gravel K, Graham ID. Barriers and facilitators to implementing shared decision-making in clinical practice: update of a systematic review of health professionals' perceptions. Patient Educ Couns. 2008;73(3):526-35.

Manuscript received on 19 April 2012. Revised version accepted for publication on 5 December 2012
RESUMEN

\section{Obstáculos en la prevención de las enfermedades cardiovasculares en entornos de atención primaria en Argentina}

Palabras clave
Objetivo. Determinar las principales barreras en la prevención de las enfermedades cardiovasculares y la aplicación de las directrices de práctica clínica en atención primaria, guiar la adecuada puesta en práctica de las directrices adaptadas de la Organización Mundial de la Salud para prevenir las enfermedades cardiovasculares, y evaluar la repercusión de la intervención en la estratificación del riesgo.

Métodos. Se llevó a cabo un estudio cualitativo dirigido a los encargados de adoptar las decisiones, los profesionales de la salud y el personal de cinco centros de atención primaria de salud, que fueron entrevistados con objeto de determinar las principales barreras. Posteriormente se diseñó y ejecutó una intervención adaptada para aplicar las directrices. Con objeto de evaluar la repercusión de la intervención sobre el tamizaje de los factores de riesgo, se llevaron a cabo un análisis anterior y posterior a la intervención mediante un examen de los registros de muestras independientes de pacientes de 40 años o mayores que acudían a cada centro.

Resultados. Las principales barreras detectadas fueron el desconocimiento de las directrices y la carencia de información sobre la prevención de las enfermedades cardiovasculares, los problemas de comunicación dentro de los equipos de salud, la falta de motivación y los problemas organizativos. Al comparar los datos previos a la intervención $(n=226)$ con los posteriores a esta $(n=234)$, se observó un incremento del tamizaje de los principales factores de riesgo: la medición de la presión arterial de 44,3 a $72,6 \%$, la determinación del colesterol de 20,7 a 49,7\%, la evaluación de la presencia de tabaquismo de 20,4 a 56,1\%, la evaluación de la presencia de diabetes de 25,5 a $93,6 \%$ y la evaluación de la presencia de un episodio vascular anterior de 33,2 a $74,3 \%$. Al inicio del estudio no se llevaba a cabo la estratificación del riesgo global, en comparación con el $45,1 \%$ de estratificación realizada posteriormente a la intervención.

Conclusiones. La determinación de las principales barreras fue útil para el diseño de una intervención adaptada. Aunque no se evaluaron los resultados clínicos, este estudio revela que la ejecución es factible, y que la mayor estratificación del riesgo constituye un primer paso en la mejora de la atención de los pacientes.

Enfermedades cardiovasculares; prevención primaria; prevención de enfermedades; Argentina. 